\title{
High excision repair cross-complementation group 1 expression is associated with favorable prognostic factors in breast cancer
}

\author{
DONG HYUN KIM, HYUNJOO LEE, DONG-HOON KIM, SEOUNG WAN CHAE, \\ JIN HEE SOHN, KYUNGEUN KIM and SUNG-IM DO \\ Department of Pathology, Kangbuk Samsung Hospital, \\ Sungkyunkwan University School of Medicine, Seoul 110-746, Republic of Korea
}

Received October 9, 2016; Accepted January 26, 2017

DOI: $10.3892 / \mathrm{ol} .2017 .6737$

\begin{abstract}
Distortion of DNA can inhibit transcription and replication, resulting in cell death. The nucleotide excision repair (NER) pathway recognizes and repairs DNA adducts. Excision repair cross-complementation group 1 (ERCC1) is a nuclease that serves a vital role in the NER pathway. Few studies have investigated ERCC1 expression in breast cancer. The aim of the present study was to analyze the association between clinicopathological features and ERCC1 expression in breast cancer. ERCC1 expression was studied in 224 invasive ductal carcinomas by immunohistochemical staining. ERCC1 expression was analyzed as an immunoreactive score, and classified into low and high expression groups. The association between immunohistochemical parameters and clinicopathological features was evaluated. High expression of ERCC1 was observed in 33 cases $(14.7 \%)$ and was statistically associated with lower $\mathrm{T}$ stage $(\mathrm{P}=0.005)$, lower tumor size $(\mathrm{P}=0.001)$, no lymph node metastasis $(\mathrm{P}=0.044)$ and no lymphovascular invasion (LVI; $\mathrm{P}=0.004)$. Additionally, high ERCC1 expression was associated with a positive estrogen receptor (ER) $(\mathrm{P}=0.006)$ and progesterone receptor $(\mathrm{PR})(\mathrm{P}=0.001)$ expression status. Non-triple-negative breast carcinoma occurred more frequently in the high expression group (97\%) than the low expression group; however, the difference was not statistically significant $(\mathrm{P}=0.056)$. Overall and disease-free survival were also not significantly different between the two groups $(\mathrm{P}=0.989$ and $\mathrm{P}=0.215$, respectively). In conclusion, high ERCC1 expression is statistically associated with lower T stage, smaller tumor size, no lymph node metastasis, no LVI, and positive ER and PR expression. This suggests that ERCC1
\end{abstract}

Correspondence to: Dr Sung-Im Do or Dr Kyungeun Kim, Department of Pathology, Kangbuk Samsung Hospital, Sungkyunkwan University School of Medicine, 29 Saemunan-Ro, Jongno, Seoul 110-746, Republic of Korea

E-mail: sungim.do@samsung.com

E-mail: ke230.kim@samsung.com

Key words: excision repair cross-complementation group 1, breast cancer, prognosis is associated with favorable prognostic parameters in breast cancer.

\section{Introduction}

Breast cancer is the most common malignancy in women worldwide. Various histological types of breast cancer have been reported, with invasive ductal carcinoma (invasive carcinoma of no special type) being the most frequently occurring type $(1,2)$. Therefore, considerable effort has been devoted to identifying factors of prognostic and therapeutic significance in invasive ductal carcinoma. The immunohistochemical expression of estrogen receptor (ER), progesterone receptor (PR) and human epithelial growth factor receptor 2 (HER2) has been widely used for predicting the prognosis of breast cancer and for providing therapeutic strategies (3). Since Perou et al (4) reported the molecular features of breast cancer cells in 2000, the improvements in molecular techniques have provided a framework to establish molecular subtypes, namely luminal A, luminal B HER2-, luminal B HER $2^{+}$, triple-negative, HER 2 type, 5 negative phenotype and basal phenotype breast cancer $(5,6)$. Breast cancer-expressed hormonal receptors, including ER and PR, or amplification of HER2, have been used in various targeted treatment approaches $(7,8)$.

A targeted therapy has not yet been established for TNBC. Therefore, chemotherapy with a platinum-based agent remains in use as a common treatment of choice for TNBC (9). Excision repair cross-complementation group 1 (ERCC1)-xeroderma pigmentosum complementation group $\mathrm{F}(\mathrm{XPF})$ complex repairs DNA damaged by anticancer agents; studies have reported that ERCC1 expression is an important factor in determining the poor response of chemotherapy $(10,11)$. Certain studies have also reported that the expression of ERCC1 in TNBC may be a predictive factor of a poor response to platinum-based chemotherapy $(12,13)$. By contrast, others studies have reported that there is no association between ERCC1 expression and TNBC $(14,15)$. Another study reported that TNBC showed the lowest ERCC1 expression among other breast cancer subtype based on the expression of hormonal receptor (16). Furthermore, these studies showed that the high expression of ERCC1 was correlated with the clinicopathological factors associated with a good prognosis $(14,15)$. 
Thus, the expression of ERCC1 in breast cancer has provided ambivalent results. Therefore, the present study evaluated the association between various clinicopathological parameters and ERCC1 expression in invasive ductal breast carcinoma. Furthermore, the study also analyzed the prognosis, depending on the level of ERCC1 expression, in this carcinoma.

\section{Materials and methods}

Patient selection. A total of 224 patients with invasive ductal breast cancer, who were diagnosed and treated at the Kangbuk Samsung Hospital (Sungkyunkwan University School of Medicine, Seoul, South Korea) between January 2006 and April 2010 were enrolled. Patients who received preoperative treatment and had other diseases were excluded. Patients who performed biopsy for pathologic diagnosis were also excluded. All studies were conducted with the prior approval of the Institutional Review Board of Kangbuk Samsung Hospital. The requirement for patient consent for publication of this study was waived. The following clinicopathological parameters were included: Patient age, presence of an extensive intraductal component (EIC), skin or chest wall invasion, Paget's disease, lymphovascular invasion (LVI), tumor borders, ER positivity, PR positivity, HER-2 positivity, triple negativity, Tumor-Node-Metastasis (TNM) stage (17), presence of lymph node metastasis, distant metastasis and mortality due to breast cancer. Histological grades were assigned using tubule formation, nuclear pleomorphism, and mitotic counts based on the modified Bloom-Richardson grading system (18). The tissue samples were formalin fixed at room temperature for more than $8 \mathrm{~h}$ and they were paraffin embedded representatively. Tissue section $(3-\mu \mathrm{m}$-thick) were stained with hematoxylin (at room temperature for $90 \mathrm{sec}$ ) and eosin (at room temperature for $40 \mathrm{sec}$ ) using Dako Coverstainer fully automated system (Dako, Agilent Technologies, Inc., Santa Clara, CA, USA) and slides from all patients were reviewed by two pathologists in a blind manner with an Olympus BX51 microscope, and the histological data such as $\mathrm{T}$ and $\mathrm{N}$ stage, and lymphatic invasion, were confirmed again. The discrepant cases were reviewed by the two pathologists together to achieve a consensus result.

Tissue microarray (TMA) construction. The surgically resected specimens were fixed in $10 \%$ buffered formalin at room temperature for $24 \mathrm{~h}$, processed and embedded in paraffin using a standard protocol. All H\&E-stained slides were reviewed and the most representative tumor area was carefully selected and marked on individual paraffin blocks. The most representative tissue core was obtained from each tumor specimen. The TMA specimens were assembled using a tissue-array instrument (TMA Master; 3D HISTECH Kft., Budapest, Hungary) consisting of thin-walled stainless steel punches and stylets for emptying and transferring the needle contents. The assembly was held in an X-Y position guide with a 1-mm increment between the individual samples, a 4-mm punch depth stop device and semiautomatic micrometers. The instrument was used to create holes in the recipient block with defined array cores. The fit needle was used to transfer the tissue cores into the recipient block. Taking into consideration the limitations of the representative areas of the tumor, duplicate 2-mm-diameter tissue cores were used from each donor block. The percentage of tissue cores with tumor was $\geq 70 \%$.

Immunohistochemistry and immunohistochemical evaluation. Immunohistochemistry analysis was performed using Leica BOND-MAX ${ }^{\mathrm{TM}}$ fully automated immunohistochemistry system, according to the manufacture's protocol (Leica Microsystems GmbH, Wetzlar, Germany). Briefly, 4- $\mu$ m-thick sections were deparaffinized and pre-treated with the Epitope Retrieval Solution 2 (EDTA-buffer $\mathrm{pH} 8.8$ ) at $98^{\circ} \mathrm{C}$ for $20 \mathrm{~min}$. After the tissue washed three times with Bond TM Wash Solution 10X concentrate (cat. no. AR9590), peroxidase blocking was performed for 10 min using the Bond Polymer Refine Detection kit DS9800 (Leica Microsystems GmbH). Tissues were again washed three times with Bond TM Wash Solution 10X concentrate (cat. no. AR9590) and then incubated with the primary antibodies at room temperature for $60 \mathrm{~min}$. Subsequently, tissues were incubated with polymer for $10 \mathrm{~min}$ and developed using 3,3-diaminobenzidine at room temperature for $10 \mathrm{~min}$. ER (cat. no. RM-9101-F; 1:200 dilution; SP1 clone; Labvision Corporation, Fremont, CA, USA), PR (cat. no. M3569; 1:200 dilution; PgR636 clone; Dako; Agilent Technologies, Inc.) and HER2 (cat. no. RM-9103-R7-A; 1:200 dilution; SP3 clone; Labvision Corporation) antibodies were used. ER and PR expression was evaluated by Allred scoring (19) and HER2 expression was evaluated by American Society of Clinical Oncology/College of American Pathologists guideline recommendations (20). In case with equivocal scores (HER2 score 2) (20), silver in situ hybridization was performed for the determination of HER2 gene status (Fig. 1).

ERCC1 immunohistochemistry staining and immunohistochemical evaluation. Human tissues obtained were fixed in $10 \%$ formalin solution at room temperature for $24 \mathrm{~h}$, dehydrated through a graded ethanol series, washed in xylene and processed for embedding in paraffin wax, according to routine protocols. Sections were incubated in a solution of $0.3 \% \mathrm{H}_{2} \mathrm{O}_{2}$ at room temperature for $15 \mathrm{~min}$ to inhibit endogenous peroxidase activity. Antigen retrieval procedure was performed using $10 \mathrm{mM}$ Tris $+1 \mathrm{mM}$ EDTA $+0.03 \%$ Tween-20 Solution for $30 \mathrm{~min}$ in a presser cooker chamber. Non-specific blocking was quenched by incubation with $4 \%$ bovine serum albumin for $30 \mathrm{~min}$. Sections were then incubated for $1 \mathrm{~h}$ at room temperature with primary antibodies against ERCC1 (cat. no. ab2356; Abcam, Cambridge, MA, USA) diluted to 1:100. The detection system EnVision+ for secondary horseradish peroxidase-conjugated mouse antibodies (cat. no. K4001; 1:2,000; Dako; Agilent Technologies, Inc.) was applied according to the manufacturer's instructions. The secondary antibodies were incubated at room temperature for $8 \mathrm{~min}$. Slides were stained with liquid diaminobenzidine tetrahydrochloride, a high-sensitivity substrate-chromogen system (cat. no. K5007; Dako; Agilent Technologies, Inc.). Counterstaining was performed with Meyer's hematoxylin at room temperature for $1 \mathrm{~min}$.

The images on the slides were visualized with an Olympus BX51 light microscope (Olympus, Tokyo, Japan). Staining intensity was scored on a scale of 0 to $3(0$, negative; 1 , weak; 

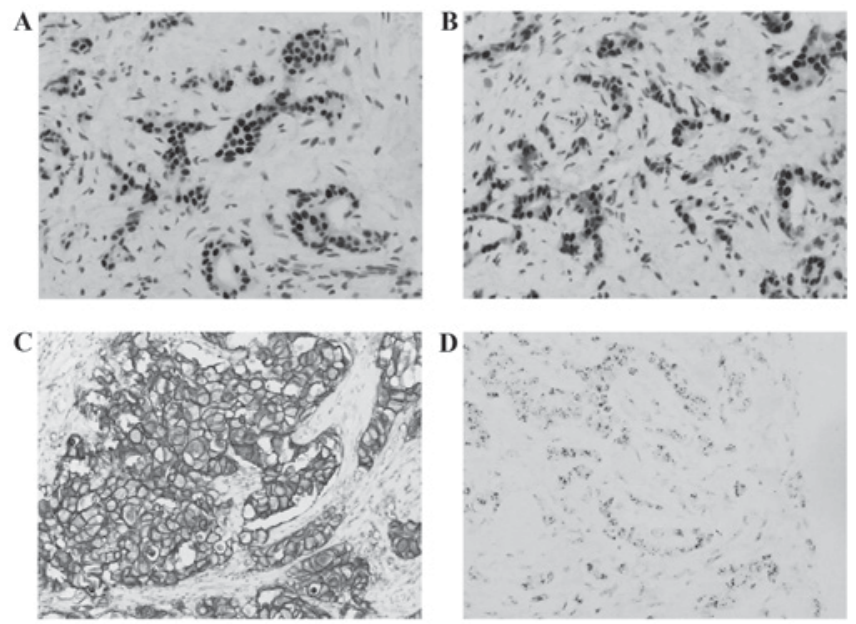

Figure 1. Immunohistochemical staining for receptors in invasive breas carcinoma. (A) Estrogen receptor (magnification, x200), (B) progesterone receptor (magnification, x200), (C) HER2 (magnification, x200) and (D) silver in situ hybridization for HER2 gene expression in breast invasive carcinoma (magnification, x1,000). HER2, human epidermal growth factor receptor-2.

2, moderate; and 3, strong) (Fig. 2). The percentage of positive cells was also classified into one of four categories: Score of 1 , $0-25 \%$; score of 2, 26-50\%; score of 3,51-75\%; and score of 4 , $76-100 \%$. When a discrepancy occurred between duplicate cores, the higher score of the two tissue cores was used as the final score. The level of staining was analyzed as an immunoreactive score (IRS), which was calculated by multiplying together the score of the staining intensity and the percentage of positive cells (21). The expression was classified into low expression (IRS $\leq 7$ ) and high expression (IRS>7) groups, according to a previous study (21).

Statistical analysis. Statistical analyses were performed with PASW Statistics for Windows, version 18.0 (SPSS, Inc., Chicago, IL, USA). The $\chi^{2}$ test, Fisher's exact test and Student's t-test were used to evaluate the associations between ERCC1 expression and clinicopathological parameters. Multivariate logistic regression analysis was used to identify the clinicopathological predictors of ERCC1 high expression. Disease-free survival (DFS) was defined from the day of surgery to the day of recurrence. Overall survival (OS) was defined from the day of diagnosis to the day of the patient mortality from breast cancer or last known follow-up. Survival probability curves were calculated by life table method, and Gehan's generalized Wilcoxon method was applied for analyzing the univariate survival clinicopathological parameters. $\mathrm{P} \leq 0.05$ was considered to indicate a statistically significant difference. Multivariate survival parameters were detected among parameters that were statistically significant in univariate analysis by applying the Cox proportional hazards model ( $95 \%$ confidence interval) with a backward stepwise elimination method.

\section{Results}

ERCC1 immunohistochemical staining was performed for all 224 invasive ductal carcinoma cases. ERCC1 showed a nuclear expression pattern in all cases. The cut-off value of IRS was 7,
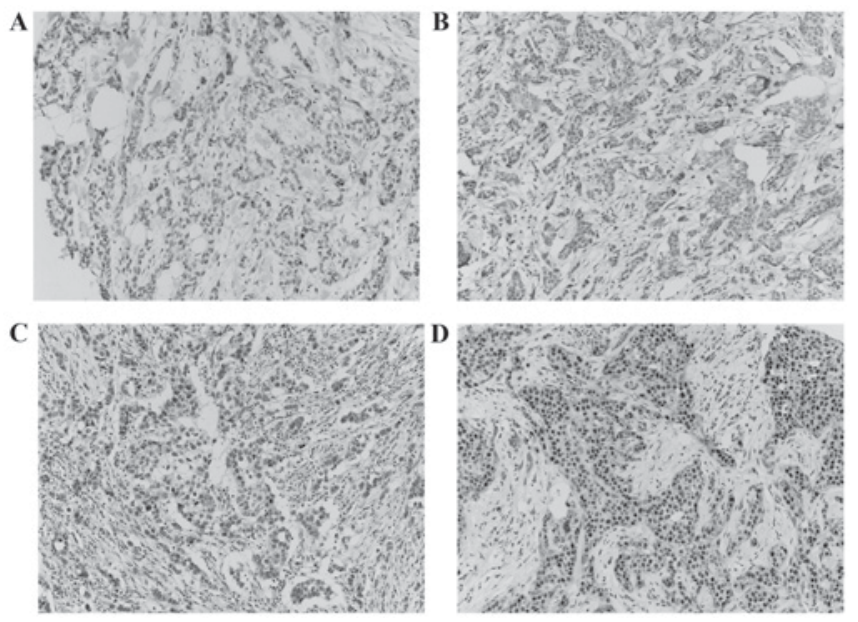

Figure 2. Immunohistochemical staining for ERCC1 in invasive breast carcinoma. (A) Negative nuclear expression for ERCC1 (magnification, x200). (B) Weak nuclear expression for ERCC1 (magnification, x200). (C) Moderate nuclear expression for ERCC1 (magnification, x200) and (D) strong nuclear expression for ERCC1 (magnification, x200). ERCC1, excision repair cross-complementation group 1.

and IRS $>7$ referred to high expression. Among the 224 cases, high expression of ERCC1 was observed in 33 cases (14.7\%). Clinicopathological and immunohistochemical parameters, including the expression of ERCC1, are shown in Table I.

With regard to the clinicopathological parameters, high expression of ERCC1 was statistically associated with smaller tumor size $(<2.0 \mathrm{~cm} ; \mathrm{P}=0.001)$, no lymph node metastasis $(\mathrm{P}=0.044)$, lower pathological stage (stage $\mathrm{I} ; \mathrm{P}=0.001)$ and no LVI $(\mathrm{P}=0.004)$. However, age $(\mathrm{P}=0.253), \mathrm{N}$ stage $(\mathrm{P}=0.131)$, histological grade $(\mathrm{P}=0.373)$, EIC $(\mathrm{P}=0.935)$, skin and chest wall invasion $(\mathrm{P}=0.442)$, Paget's disease $(\mathrm{P}=0.999)$, the presence of metastasis $(\mathrm{P}=0.750)$ and the recurrence rate $(\mathrm{P}=0.999)$ were not statistically associated with ERCC1 expression (Table II). To detect parameters that were independently associated with high expression of ERCC1, the four parameters found to be significant on univariate analysis were analyzed by multivariate logistic regression analysis. It was found that smaller tumor size $(<2.0 \mathrm{~cm} ; \mathrm{P}=0.002$ relative risk, $3.815 ; 95 \%$ confidence interval, 1.638-8.888), no lymph node metastasis $(\mathrm{P}=0.048$; relative risk, 2.229; 95\% confidence interval, 1.007-4.9340), lower pathological stage (stage $\mathrm{I} ; \mathrm{P}=0.001$; relative risk, 3.617; 95\% confidence interval, 1.685-7.764) and no LVI ( $\mathrm{P}=0.007$; relative risk, 3.608; 95\% confidence interval, 1.424-9.141) were independent clinicopathological parameters in accordance with the high expression of ERCC1 (Table II).

With regard to immunohistochemical parameters, high expression of ERCC1 was associated with positive ER $(\mathrm{P}=0.006)$ and $\mathrm{PR}(\mathrm{P}=0.001)$ expression. Non-triple-negative breast carcinoma (TNBC) occurred more frequently in the high expression group (97\%) than the low expression group, however, the difference was not statistically significant $(\mathrm{P}=0.056)$. Additionally, HER2 expression was also not associated with ERCC1 expression. Multivariate logistic regression analysis was also applied for the detection of independent parameters that were associated with the high expression of ERCC1. It was found that positive ER ( $\mathrm{P}=0.012$; relative risk, 4.806; 95\% confidence interval, 1.412-16.359) 
Table I. Clinicopathological parameters and immunohistochemical results.

\begin{tabular}{lll}
\hline Parameter & No. & $\%$ \\
\hline
\end{tabular}

Age, years
$\leq 52$
$>52$

$>52$

T stage

1

2

102

3

4

11

0

Tumor size, $\mathrm{cm}$

$$
\begin{aligned}
& \leq 2.0 \\
& >2.0
\end{aligned}
$$

$\mathrm{N}$ stage

$$
0
$$$$
1
$$$$
2
$$$$
3
$$

TMN stage

Lymph node metastasis

$\begin{array}{ll}\text { Absence } & 120 \\ \text { Presence } & 104 \\ \text { Histological grade } & \\ 1 & 54 \\ 2 & 99 \\ 3 & 71 \\ \text { EIC } & \end{array}$

$$
\text { Absence } 189
$$

Presence

Skin and chest wall invasion

$\begin{array}{lr}\text { Absence } & 197 \\ \text { Presence } & 5 \\ \text { Not examined } & 22 \\ \text { Paget's disease } & \\ \text { Absence } & 205 \\ \text { Presence } & 4 \\ \text { Not examined } & 15 \\ \text { Lympho-vascular invasion } & \end{array}$

$\begin{array}{lr}\text { Absence } & 133 \\ \text { Presence } & 91 \\ \text { ER } & \end{array}$

Negative 65

Positive 159

PR

Negative

Positive

53.6

33.4

47.8

17.9
Table I. Continued.

\begin{tabular}{lrr}
\hline Parameter & No. & $\%$ \\
\hline HER2 & & \\
Negative & 167 & 74.6 \\
Positive & 57 & 25.4 \\
Triple-negative & & \\
Yes & 32 & 14.3 \\
No & 192 & 85.7 \\
Distant metastasis & & \\
Absence & 202 & 90.2 \\
Presence & 22 & 9.8 \\
ERCC1 & & \\
Low & 191 & 14.7 \\
High & 33 & \\
\hline
\end{tabular}

EIC, extensive intraductal component; ER, estrogen receptor; PR, progesterone receptor; HER2, human epidermal growth factor 2; ERCC1, excision repair cross complementation 1; TNM, Tumor-Node-Metastasis.

and positive $\mathrm{PR}(\mathrm{P}=0.003$; relative risk, 6.325 ; $95 \%$ confidence interval, 1.864-21.466) expression are independent immunohistochemical parameters that correspond to the high expression of ERCC1 (Table III).

The 5-year OS rate for all patients in this study was $95.1 \%$ (213/224 patients). In the high expression group, the 5-year OS rate was $100 \%$ (33/33 patients). In the low expression group, 24.1 the 5-year OS rate was $94.2 \%$ (180/191 patients). ERCC1 44.2 expression was not statistically associated with the OS rate $31.7(\mathrm{P}=0.375)$. The 5-year DFS rate for all patients in this study was $85.7 \%$ (192/224 patients). In the high expression group, the 5 -year DFS rate was $87.9 \%$ (29/33 patients). In the low expres84.4 sion group, the 5-year DFS rate was $85.3 \%$ (163/191 patients). 15.6 ERCC1 expression was also not statistically associated with the DFS rate $(\mathrm{P}=0.999)$.

To evaluate OS, univariate analysis was performed. Advanced $\mathrm{T}$ stage ( $\mathrm{T}$ stage 2-3; $\mathrm{P}=0.006$ ), presence of lymph node metastasis $(\mathrm{P}=0.038)$, advanced pathological stage (stage 2-3; $\mathrm{P}=0.023)$, presence of skin and chest wall invasion $(\mathrm{P}=0.015)$, presence of LVI $(\mathrm{P}=0.011)$ and presence of distant 91.5 metastasis $(\mathrm{P}=0.001)$ were statistically associated with poor 1.8 OS. Status of ERCC1 expression and immunohistochemical 6.7 parameters were not associated with OS. Multivariate analysis for OS was performed using these statistically significant parameters. It was found that advanced $\mathrm{T}$ stage $(\mathrm{P}=0.034$; hazard ratio, 9.283; 95\% confidence interval, 1.188-72.538), presence of lymph node metastasis $(\mathrm{P}=0.04$; hazard ratio, 4.989; 95\% confidence interval, 1.078-23.097), presence of skin and chest wall invasion ( $\mathrm{P}=0.001$; hazard ratio, $12.647 ; 95 \%$ confidence interval, 2.718-58.839), presence of LVI ( $\mathrm{P}=0.017$; hazard ratio, 6.448; 95\% confidence interval, 1.393-29.854) and presence of distance metastasis $(\mathrm{P}=0.000$; hazard ratio, $22.361 ; 95 \%$ confidence interval, 6.486-77.095) independently 65.6 predicted poor OS (Table IV). 
Table II. Association between ERCC1 expression and clinicopathological parameters.

\begin{tabular}{|c|c|c|c|c|c|}
\hline \multirow[b]{3}{*}{$\begin{array}{l}\text { Clinicopathological } \\
\text { parameters }\end{array}$} & \multicolumn{3}{|c|}{ Univariate analysis } & & \\
\hline & \multirow{2}{*}{$\begin{array}{c}\text { ERCC low } \\
\text { expression } \\
(\text { IRS } \leq 7) \\
\text { n }(\%)\end{array}$} & \multirow{2}{*}{$\begin{array}{c}\text { ERCC high } \\
\text { expression } \\
(\text { IRS }>7) \\
\text { n }(\%)\end{array}$} & & \multicolumn{2}{|c|}{ Multivariate analysis } \\
\hline & & & P-value & $\begin{array}{c}\mathrm{RR} \\
(95 \% \mathrm{CI})\end{array}$ & P-value \\
\hline Age, years & & & 0.253 & & \\
\hline$\leq 52$ & $107(56.0)$ & $22(66.7)$ & & Not applicable & \\
\hline$>52$ & $84(44.0)$ & $11(33.3)$ & & & \\
\hline Tumor size, $\mathrm{cm}$ & & & $0.001^{\mathrm{a}}$ & & $0.002^{\mathrm{a}}$ \\
\hline$\leq 2.0$ & $86(45.0)$ & $25(75.8)$ & & $3.815(1.638-8.888)$ & \\
\hline$>2.0$ & $105(55.0)$ & $8(24.2)$ & & & \\
\hline $\mathrm{N}$ stage & & & 0.131 & & \\
\hline 0 & $97(50.8)$ & $23(69.7)$ & & Not applicable & \\
\hline 1 & $58(30.4)$ & $8(24.2)$ & & & \\
\hline 2 & $19(9.9)$ & $2(6.1)$ & & & \\
\hline 3 & $17(8.9)$ & $0(0.0)$ & & & \\
\hline Lymph node metastasis & & & $0.044^{\mathrm{a}}$ & & $0.048^{\mathrm{a}}$ \\
\hline Absence & $97(50.8)$ & $23(69.7)$ & & $2.229(1.007-4.934)$ & \\
\hline Presence & $94(49.2)$ & $10(30.3)$ & & & \\
\hline \multicolumn{6}{|l|}{ TNM stage } \\
\hline 1 & $57(29.8)$ & $20(60.6)$ & $0.001^{\mathrm{a}}$ & $3.617(1.685-7.764)$ & $0.001^{\mathrm{a}}$ \\
\hline 2 and 3 & $134(70.2)$ & $13(39.4)$ & & & \\
\hline Histological grade & & & 0.373 & & \\
\hline 1 & $45(23.6)$ & $9(27.3)$ & & Not applicable & \\
\hline 2 & $82(42.9)$ & $17(51.5)$ & & & \\
\hline 3 & $64(33.5)$ & $7(21.2)$ & & & \\
\hline EIC & & & 0.935 & & \\
\hline Absence & $161(84.3)$ & $28(84.8)$ & & Not applicable & \\
\hline Presence & $30(15.7)$ & $5(15.2)$ & & & \\
\hline Skin and chest wall invasion ${ }^{a}$ & & & 0.442 & & \\
\hline Absence & $176(97.8)$ & $21(95.5)$ & & Not applicable & \\
\hline Presence & $4(2.2)$ & $1(4.5)$ & & & \\
\hline Paget's disease ${ }^{b}$ & & & 0.999 & & \\
\hline Absence & $176(97.8)$ & $29(100)$ & & Not applicable & \\
\hline Presence & $4(2.2)$ & $0(0)$ & & & \\
\hline Lymphovascular invasion & & & $0.004^{\mathrm{a}}$ & & $0.007^{\mathrm{c}}$ \\
\hline Absence & $106(55.5)$ & $27(81.8)$ & & $3.608(1.424-9.141)$ & \\
\hline Presence & $85(44.5)$ & $6(18.2)$ & & & \\
\hline Distant metastasis & & & 0.750 & & \\
\hline Absence & $171(89.5)$ & $31(93.9)$ & & Not applicable & \\
\hline Presence & $20(10.5)$ & $2(6.1)$ & & & \\
\hline Recurrence & & & 0.999 & & \\
\hline Negative & $163(85.3)$ & $29(87.9)$ & & Not applicable & \\
\hline Positive & $28(14.7)$ & $4(12.1)$ & & & \\
\hline
\end{tabular}

${ }^{a}$ Medical records regarding skin and chest wall invasion were missing for 22 patients; ${ }^{b}$ medical records regarding Paget's disease were missing

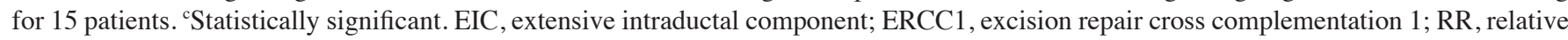
risk; IRS, immunoreactive score; TNM, Tumor-Node-Metastasis. 
Table III. Association between ERCC1 expression and immunohistochemical results.

\begin{tabular}{|c|c|c|c|c|c|}
\hline \multirow[b]{3}{*}{$\begin{array}{l}\text { Immunohistochemical } \\
\text { results }\end{array}$} & \multicolumn{3}{|c|}{ Univariate analysis } & \multirow{2}{*}{\multicolumn{2}{|c|}{ Multivariate analysis }} \\
\hline & \multirow{2}{*}{$\begin{array}{c}\text { ERCC low } \\
\text { expression } \\
(\text { IRS } \leq 7)\end{array}$} & \multirow{2}{*}{$\begin{array}{c}\text { ERCC high } \\
\text { expression } \\
(\text { IRS }>7)\end{array}$} & \multirow[b]{2}{*}{ P-value } & & \\
\hline & & & & $\begin{array}{c}\mathrm{RR} \\
(95 \% \mathrm{CI})\end{array}$ & P-value \\
\hline ER & & & $0.006^{\mathrm{a}}$ & & $0.012^{\mathrm{a}}$ \\
\hline Negative & $62(32.5)$ & $3(9.1)$ & & $4.806(1.412-16.359)$ & \\
\hline Positive & $129(67.5)$ & $30(90.9)$ & & & \\
\hline PR & & & $0.001^{\mathrm{a}}$ & & $0.003^{\mathrm{a}}$ \\
\hline Negative & $74(38.7)$ & $3(9.1)$ & & $6.325(1.864-21.466)$ & \\
\hline Positive & $117(61.3)$ & $30(90.9)$ & & & \\
\hline HER 2 & & & 0.299 & & \\
\hline Negative & $140(73.3)$ & $27(81.8)$ & & Not applicable & \\
\hline Positive & $51(26.7)$ & $6(18.2)$ & & & \\
\hline Triple-negative & & & 0.056 & & \\
\hline No & $160(83.8)$ & $32(97.0)$ & & Not applicable & \\
\hline Yes & $31(16.2)$ & $1(3.0)$ & & & \\
\hline
\end{tabular}

${ }^{\text {aS }}$ tatistically significant. ER, estrogen receptor; PR, progesterone receptor; HER2, human epidermal growth factor 2; ERCC1, excision repair cross complementation 1; IRS, immunoreactive score; RR, relative risk.

To evaluate DFS, univariate analysis was performed. Advanced $\mathrm{T}$ stage $(\mathrm{P}=0.007)$, high histological grade $(\mathrm{P}=0.035)$, presence of skin and chest wall invasion $(\mathrm{P}=0.001)$, presence of LVI $(\mathrm{P}=0.022)$, presence of distance metastasis $(\mathrm{P}=0.001)$, loss of $\mathrm{PR}$ expression $(\mathrm{P}=0.020)$ and triple-negative subtype $(\mathrm{P}=0.002)$ were statistically associated with a shorter DFS time. Multivariate analysis for DFS was performed using these statistically significant parameters. It was found that advanced $\mathrm{T}$ stage $(\mathrm{P}=0.008$; hazard ratio, 2.968 ; $95 \%$ confidence interval, 1.333-6.607), presence of skin and chest wall invasion $(\mathrm{P}=0.001$; hazard ratio, 8.991 ; $95 \%$ confidence interval, 2.713-27.796), presence of LVI $(\mathrm{P}=0.027$; hazard ratio, 2.22; 95\% confidence interval, 1.096-4.497), presence of distance metastasis $(\mathrm{P}=0.001$; hazard ratio, 16.016; 95\% confidence interval, 7.790-32.929), loss of $\mathrm{PR}$ expression ( $\mathrm{P}=0.037$; hazard ratio, 2.091; 95\% confidence interval, 1.045-4.184) and triple-negative subtype $(\mathrm{P}=0.005$; hazard ratio, 3.020 ; $95 \%$ confidence interval, 1.395-6.537) independently predicted a shorter DFS time (Table IV).

\section{Discussion}

There are four major pathways to repair damaged DNA: NER, base excision repair, mismatch repair and double strand break repair (22). Among these pathways, NER plays an important role in recognizing and repairing the DNA adducts, particularly those induced by chemotherapeutic agents such as cisplatin (10). The NER pathway requires a number of factors. Among these factors, ERCC1 serves an essential role for the incision step and completion of the NER pathway (11). ERCC1 bind to XPF and forms the ERCC1-XPF complex $(10,11)$. The ERCC1-XPF complex is important as a structure-specific endonuclease in the NER pathway (11). Therefore, certain studies have reported that the ERCC1-XPF complex can be an important factor for repairing the DNA damage induced by chemotherapeutic agents, including cisplatin; thus, the expression of ERCC1 has been considered as a predictive factor for resistance to platinum-based chemotherapy $(10,11)$.

Certain studies have reported the association between ERCC1 expression and TNBC. Sidoni et al (12) reported that one-third of the triple-negative patients exhibited relevant ERCC1 expression. Additionally, Ozkan et al (13) reported that two-thirds of the triple-negative patients exhibited ERCC1 expression.

However, recently, good prognostic effects of ERCC1 expression have been reported by certain researchers. Goyal et al (14) reported that the overexpression of ERCC1 was associated with lower $\mathrm{T}$ stage, nodal negativity, an age $>50$ years and ER positivity, but was not associated with OS and DFS. Gerhard et al (15) reported that ERCC1 expression was significantly associated with smaller tumor size and ER positivity, but was not associated with OS and DFS. These two studies also reported that the triple-negative immunohistochemical phenotype was not statistically associated with ERCC1 expression. Furthermore, one report demonstrated that the level of ERCC1 expression was the lowest in triple-negative phenotypes compared with other phenotypes, and that negativity for ERCC1 expression occurred more frequently in TNBC and luminal B group breast cancer (16).

By contrast, other studies did not find any association between ERCC1 expression and clinical and immunohistochemical parameters. Fu et al (23) found that ERCC1 gene expression detected by reverse transcription-polymerase chain reaction was not significantly associated with age, tumor size, axillary lymph node metastasis, pathological type, histological grade, ER, PR or HER-2. Metro et al (24) also reported that 


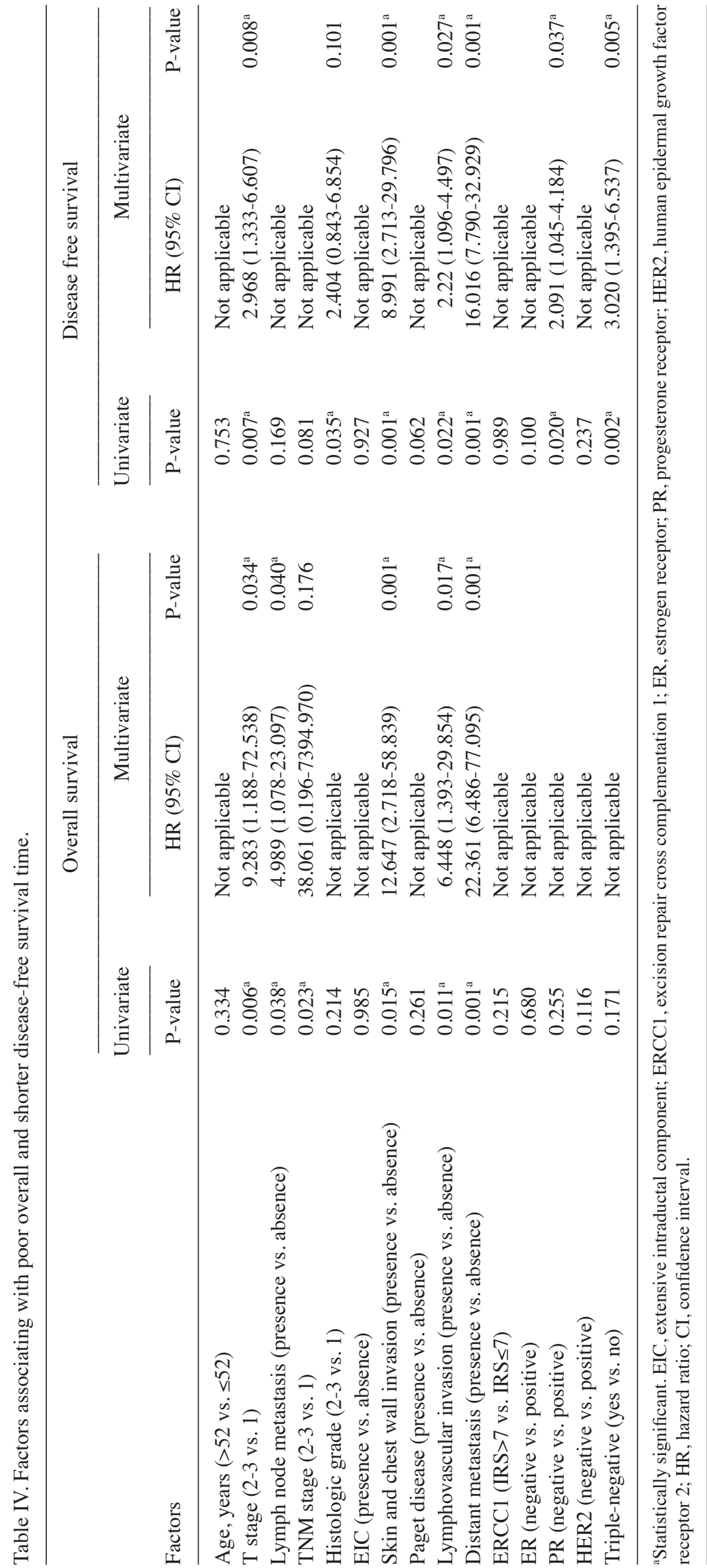


there was no significant association between in situ protein expression of ERCC1 and various clinico-pathological parameters, including age, tumor stage at diagnosis, histology, hormone receptor status, HER-2 status, presence of visceral disease and pretreatment of metastatic disease.

Besides cases of breast cancer, in cases of non-small cell lung cancer and gastric cancer, a association has been reported between ERCC1 expression and good prognosis. Lee et al (25) showed that in patients with resected non-small cell lung cancer, ERCC1 expression was an independent prognostic factor of longer survival, and that EGFR mutation was more frequent in ERCC1-negative patients. Another study also showed that in patients with resected non-small cell lung cancer, the 5-year survival rate of ERCC1-positive patients was longer than that of ERCC1-negative patients (76 vs. $49 \%$, $\mathrm{P}=0.004)$ (26). Wang et al (27) reported that ERCC1 expression may be a good prognostic factor in patients with resected gastric cancer.

In addition, Han et al (28) reported that single nucleotide polymorphism (SNP)-SNP interaction of NER pathway genes increased the risk of breast cancer. Another study reported that ERCC polymorphism was associated with the increase in the breast cancer risk (29). Notably, Mo et al (30) reported that the mRNA level of ERCC1 expression was significantly associated with water arsenic concentration and nail arsenic concentration. Moreover, the study suggested that the DNA repair response was induced by arsenic exposure. Therefore, high ERCC1 expression may be a compensatory response against the DNA injury that is induced by various carcinogens.

In the present study, the immunohistochemical expression of ERCC1 was analyzed in patients with invasive ductal carcinoma. ERCC1 high expression (IRS>7) was statistically associated with the smaller tumor size $(\leq 2 \mathrm{~cm})$, no lymph node metastasis, low pathological stage (TNM stage 1) and no LVI. In addition, high ERCC1 expression was statistically associated with positive estrogen receptor (ER) and progesterone receptor (PR) expression. The triple-negative phenotype was frequently expressed in the ERCC1 low expression group, but this result was not statistically significant. ERCC1 expression was not statistically associated with OS and DFS. Higher T stage (stage 2-3), the presence of skin and chest wall invasion, and LVI were independent of predictive factors of poor OS and shorter DFS. The presence of lymph node metastasis was associated with poor OS only. No immunohistochemical parameters influenced the OS, but the negative expression of PR and triple-negative status were statistically associated with a shorter DFS time. Although ERCC1 expression was not a direct predictor of OS and DFS, low T stage (size $\leq 2 \mathrm{~cm}$ ), no lymph node metastasis and no LVI were significantly associated with the high expression of ERCC1. Therefore, the high expression of ERCC1 may be a more favorable factor of good OS and longer DFS times than low level ERCC1 expression.

In conclusion, in the present study, high ERCC1 expression was associated with several clinical and immunohistochemical parameters, namely lower T stage, smaller tumor size, no lymph node metastasis, no LVI, and positivity for ER and $\mathrm{PR}$ in invasive ductal carcinoma of the breast. However, no association was shown between the expression of ERCC1 and OS and DFS rate. Based on the results of previously reviewed studies, the role of ERCC1 is not yet fully understood. In order to evaluate the complete role of ERCC1 and the association between ERCC1 expression and clinical outcomes, a greater number of large-scale studies may be required.

\section{References}

1. Li CI, Anderson BO, Daling JR and Moe RE: Trends in incidence rates of invasive lobular and ductal breast carcinoma. JAMA 289: 1421-1424, 2003

2. Li CI, Uribe DJ and Daling JR: Clinical characteristics of different histologic types of breast cancer. Br J Cancer 93: 1046-1052, 2005

3. Subramaniam S, Bhoo-Pathy N, Taib NA, Tan GH, See MH, Jamaris S, Ho GF, Looi LM and Yip CH: Breast cancer outcomes as defined by the estrogen receptor, progesterone receptor and human growth factor receptor-2 in a multi-ethnic Asian country. World J Surg 39: 2450-2458, 2015.

4. Perou CM, Sorlie T, Eisen MB, van de Rijn M, Jeffrey SS, Rees CA, Pollack JR, Ross DT, Johnsen H, Akslen LA, et al: Molecular portraits of human breast tumours. Nature 406: 747-752, 2000

5. Schnitt SJ: Classification and prognosis of invasive breast cancer: From morphology to molecular taxonomy. Mod Pathol 23 (Suppl 2): S60-S64, 2010.

6. Engstrom MJ, Opdahl S, Hagen AI, Romundstad PR, Akslen LA, Haugen OA, Vatten LJ and Bofin AM: Molecular subtypes, histopathological grade and survival in a historic cohort of breast cancer patients. Breast Cancer Res Treat 140: 463-473, 2013.

7. Parise CA and Caggiano V: Breast Cancer Survival Defined by the ER/PR/HER2 Subtypes and a Surrogate Classification according to Tumor Grade and Immunohistochemical Biomarkers. J Cancer Epidemiol 2014: 469251, 2014.

8. Gajria D and Chandarlapaty S: HER2-amplified breast cancer: Mechanisms of trastuzumab resistance and novel targeted therapies. Expert Rev Anticancer Ther 11: 263-275, 2011.

9. Hudis CA and Gianni L: Triple-negative breast cancer: An unmet medical need. Oncologist 16 (Suppl 1): S1-S11, 2011.

10. Kirschner K and Melton DW: Multiple roles of the ERCC1-XPF endonuclease in DNA repair and resistance to anticancer drugs. Anticancer Res 30: 3223-3232, 2010.

11. McNeil EM and Melton DW: DNA repair endonuclease ERCC1-XPF as a novel therapeutic target to overcome chemoresistance in cancer therapy. Nucleic Acids Res 40: 9990-10004, 2012.

12. Sidoni A, Cartaginese F, Colozza M, Gori S and Crinó L: ERCC1 expression in triple negative breast carcinoma: The paradox revisited. Breast Cancer Res Treat 111: 569-570, 2008.

13. Ozkan C, Gumuskaya B, Yaman S, Aksoy S, Guler G and Altundag K: ERCC1 expression in triple negative breast cancer. J BUON 17: 271-276, 2012.

14. Goyal S, Parikh RR, Green C, Schiff D, Moran MS, Yang Q and Haffty BG: Clinicopathologic significance of excision repair cross-complementation 1 expression in patients treated with breast-conserving surgery and radiation therapy. Int J Radiat Oncol Biol Phys 76: 679-684, 2010.

15. Gerhard R, Carvalho A, Carneiro V, Bento RS, Uemura G, Gomes M, Albergaria A and Schmitt F: Clinicopathological significance of ERCC1 expression in breast cancer. Pathol Res Pract 209: 331-336, 2013.

16. Kim D, Jung W and Koo JS: The expression of ERCC1, RRM1, and BRCA1 in breast cancer according to the immunohistochemical phenotypes. J Korean Med Sci 26: 352-359, 2011.

17. Edge SB: American Joint Committee On Cancer, AJCC Cancer Staging Manual. 8th edition. Springer, New York, NY, 2010.

18. O'Malley FP and Pinder SE (eds): Breast pathology, Churchill Livingstone, Elsevier, Edinburgh, 2006.

19. Nadji M, Gomez-Fernandez C, Ganjei-Azar P and Morales AR: Immunohistochemistry of estrogen and progesterone receptors reconsidered: Experience with 5,993 breast cancers. Am J Clin Pathol 123: 21-27, 2005.

20. Wolff AC, Hammond ME, Hicks DG, Dowsett M, McShane LM, Allison KH, Allred DC, Bartlett JM, Bilous M, Fitzgibbons P, et al: Recommendations for human epidermal growth factor receptor 2 testing in breast cancer: American Society of Clinical Oncology/College of American Pathologists clinical practice guideline update. J Clin Oncol 31: 3997-4013, 2013. 
21. Remmele W and Stegner HE: Recommendation for uniform definition of an immunoreactive score (IRS) for immunohistochemical estrogen receptor detection (ER-ICA) in breast cancer tissue. Pathologe 8: 138-140, 1987 (In German).

22. Kelland L: The resurgence of platinum-based cancer chemotherapy. Nat Rev Cancer 7: 573-584, 2007.

23. Fu JM, Zhou J, Xie JS and Li H: Effect of neoadjuvant chemotherapy on ERCC1 gene expression in breast cancer. Nan Fang Yi Ke Da Xue Xue Bao 28: 603-605, 2008 (In Chinese).

24. Metro G, Zheng Z, Fabi A, Schell M, Antoniani B, Mottolese M, Monteiro AN, Vici P, Lara Rivera S, Boulware D, et al: In situ protein expression of RRM1, ERCC1, and BRCA1 in metastatic breast cancer patients treated with gemcitabine-based chemotherapy. Cancer Invest 28: 172-180, 2010.

25. Lee KH, Min HS, Han SW, Oh DY, Lee SH, Kim DW, Im SA, Chung DH, Kim YT, Kim TY, et al: ERCC1 expression by immunohistochemistry and EGFR mutations in resected non-small cell lung cancer. Lung Cancer 60: 401-407, 2008.
26. Seyhan EC, Altin S, Cetinkaya E, Sökücü S, Abali H, Buyukpinarbasili N and Fener N: Prognostic significance of ERCC1 expression in resected non small cell lung carcinoma. Ann Thorac Cardiovasc Surg 17: 110-117, 2011.

27. Wang J, Zhou XQ, Li JY, Cheng JF, Zeng XN, Li X and Liu P. Prognostic significance of ERCC1 expression in postoperative patients with gastric cancer. Chin J Cancer Res 26: 323-330, 2014.

28. Han W, Kim KY, Yang SJ, Noh DY, Kang D and Kwack K: SNP-SNP interactions between DNA repair genes were associated with breast cancer risk in a Korean population. Cancer 118: 594-602, 2012.

29. Mojgan H, Massoud $\mathrm{H}$ and Ahmad E: ERCC1 intron 1 was associated with breast cancer risk. Arch Med Sci 8: 655-658, 2012.

30. Mo J, Xia Y, Ning Z, Wade TJ and Mumford JL: Elevated ERCC1 gene expression in blood cells associated with exposure to arsenic from drinking water in Inner Mongolia. Anticancer Res 29: 3253-3259, 2009. 